\title{
PERBEDAAN SARANG ALAMI DENGAN SEMI ALAMI MEMPENGARUHI MASA INKUBASI DAN KEBERHASILAN MENETAS TELUR PENYU LEKANG (Lepidochelys olivacea) PANTAI BOOM BANYUWANGI
}

\section{The Difference between Natural with Semi-natural Nest Conduct The Incubation Period and Hatching Rate of Lekang Turtle's Egg (Lepidochelys olivacea) in Boom Seashore Banyuwangi}

\author{
Sabrina Hatoguan Samosir ${ }^{1 *}$, Tatik Hernawati ${ }^{2}$, Aditya Yudhana ${ }^{3}$, \\ Wiyanto Haditanojo ${ }^{4}$ \\ ${ }^{1}$ Mahasiswa Pendidikan Dokter Hewan, \\ ${ }^{2}$ Departemen Reproduksi Veteriner, \\ ${ }^{3}$ Departemen Parasitologi Veteriner, \\ ${ }^{4}$ Banyuwangi Sea Turtle Foundation, \\ Fakultas Kedokteran Hewan, Universitas Airlangga, \\ Kampus C Mulyorejo, Surabaya, Jawa Timur, Indonesia, 60115 \\ Telp. (031)5993016, Fax. (031)5993015 \\ *Corresponding author: sabrinahatoguan@gmail.com
}

\begin{abstract}
Abstrak
Penelitian ini bertujuan mengetahui pengaruh kondisi lingkungan dalam aspek $\mathrm{pH}$, suhu dan kelembaban antara sarang alami dengan sarang semi alami terhadap presentase daya tetas dan masa inkubasi telur Penyu Lekang (Lepidochelys olivacea) di kawasan Pantai Boom Banyuwangi. Sampel dipilih dengan metode purposive sampling berupa 20 telur Penyu Lekang yang berasal dari satu induk yang sama. Telur Penyu Lekang yang di inkubasi pada sarang alami dan sarang semi alami masing-masing berjumlah 10 butir. Rancangan penelitian menggunakan metode deskriptif, dengan melakukan observasi terhadap kondisi lingkungan antara sarang alami dengan semi alami. Uji $t$ independent digunakan untuk membandingkan presentase daya tetas. Analisis dilakukan dengan program SPSS. Hasil penelitian menunjukkan presentase daya tetas pada sarang alami berbeda sangat nyata dengan sarang semi alami, sedangkan masa inkubasi tidak dapat diambil data. Presentase daya tetas pada sarang alami lebih baik dibandingkan dengan sarang semi alami. Sarang semi alami memiliki pH yang lebih asam dibandingkan $\mathrm{pH}$ pada sarang alami. Simpulan penelitian ini terdapat perbedaan kondisi lingkungan pada aspek $\mathrm{pH}$, suhu, dan kelembaban antara sarang alami dan sarang semi alami yang mempengaruhi masa inkubasi dan daya tetas telur Penyu Lekang.
\end{abstract}

Kata kunci: sarang alami, semi alami, Penyu Lekang, Lepidochelys olivacea, Banyuwangi

\section{Abstract}

This study aims to determine the influence of environmental conditions, in the aspect of $p H$, temperature and humidity between natural and semi-natural nest of hatching percentage and incubation period of sea turtle eggs (Lepidochelys olivacea) in Boom Beach, Banyuwangi. The sample was chosen by purposive sampling method of 20 sea turtle eggs collecting from the same female. Sea turtle eggs that are incubated in natural nest and semi-natural nest respectively amounted to 10 eggs. Research design using descriptive method, which observed the environmental conditions between natural and semi-natural nest. Independent sample t test is used to compare the percentage of hatchability and was analyze with SPSS program. The results showed the percentage of hatching in natural nest was very different with semi-natural nest, while the incubation period could not be taken of data. The percentage of hatchability in natural nests is better than semi-natural nest. The pH of the nest is a major factor in the hatching percentage and the incubation period, semi-natural nest has more acidic sands than natural nest. There were differences in environmental conditions in aspects of pH, temperature and humidity that influence of hatching percentage and incubation period of sea turtle eggs (Lepidochelys olivacea).

Key words: natural nest, semi-natural nest, Lekang turtle, Lepidochelys olivacea, Banyuwangi 


\section{PENDAHULUAN}

Indonesia merupakan negara kepulauan terbesar di dunia (Lasabuda, 2013) yang memiliki kekayaan dan keanekaragaman hayati laut. Salah satu kekayaan laut Indonesia adalah penyu. Penyu telah dimasukkan ke dalam Appendix I CITES (Convention of International Trade in Endangered Species) sebagai hewan yang terancam punah.

Terdapat banyak faktor yang mempengaruhi status kepunahan penyu saat salah satunya adalah rendahnya keberhasilan daya tetas telur yang dipengaruhi oleh perubahan iklim dan suhu (Ditmer and Stapleton, 2012). Keberhasilan menetas telur penyu dipengaruhi oleh beberapa faktor, salah satunya kondisi lingkungan sarang (Rudiana, 2004).

Kondisi lingkungan pada sarang alami merupakan kondisi terbaik untuk penetasan telur penyu (Direktorat Konservasi dan Taman Nasional Laut, 2009), namun karena sulitnya pengawasan, ancaman predator, dan sebagainya maka perlu dilakukan upaya relokasi atau pemindahan telur penyu ke sarang semi alami sebagai upaya konservasi. Penetasan semi alami memiliki daya tetas yang optimal apabila persentase keberhasilan penetasan mencapai 80\% (Purwanasari, 2006). Aspek biologi dan ekologi lingkungan penetasan telur penyu, perlu dipelajari sehingga diperoleh penetasan dengan hasil yang optimal.

Banyuwangi Sea Turtle Foundation (BSTF) merupakan organisasi nirlaba yang berupaya untuk melestarikan populasi penyu di Banyuwangi, khususnya di Pantai Boom, Banyuwangi. dengan menggunakan sarang semi alami sebagai media penetasan telur penyu, namun pada tahun 2016 dan 2017 BSTF mengalami penurunan keberhasialan penetasan telur Penyu Lekang. Daya tetas yang dihasilkan tidak mencapai persentase $80 \%$.

Berdasarkan keterangan tersebut maka peneliti ingin melakukan perbandingan kondisi lingkungan antara sarang alami dan semi alami yang berada di kawasan Pantai Boom Banyuwangi. Kondisi lingkungan sarang yang diamati terdiri dari tiga aspek, yaitu suhu, kelembaban dan $\mathrm{pH}$.

\section{METODE PENELITIAN}

Penelitian ini dilaksanakan di sarang alami Pantai Boom yang dibuat oleh induk Penyu Lekang, yang tidak terkena pasang air laut dan penetasan sarang semi alami milik BSTF yang berada di kawasan Pantai Boom, Banyuwangi. Aspek yang diamati adalah pengukuran $\mathrm{pH}$, suhu dan kelembaban.

Bahan yang digunakan pada penelitian ini yaitu 20 telur Penyu Lekang (Lepidochelys olivacea) yang masing-masing diletakkan di sarang alami dan sarang semi alami dengan kedalaman sarang dan dari induk yang sama. Media yang digunakan adalah pasir yang berada di lokasi penetasan yaitu Pantai Boom dan di sarang semi alami yayasan BSTF. Sementara alat-alat yang digunakan yaitu yaitu termometer raksa untuk mengukur suhu, soil tester untuk mengukur kelembaban maupun $\mathrm{pH}$, pita meter untuk mengukur panjang dan lebar penyu, roll meter untuk mengukur kedalaman sarang dan jarak pantai, senter, kamera Sony a 5000, stopwatch, sekop untuk menggali pasir, pipa paralon untuk membantu penggalian pasir, glove, ember plastik untuk wadah memindahkan 10 telur penyu ke sarang semi alami, batang pohon dan kawat jaring untuk melindungi sarang alami dari predator.

Penelitian ini menggunakan metode deskriptif berdasarkan hasil penetasan (hatching) dan lama masa inkubasi telur. Perbandingan tingkat keberhasilan penetasan telur antara sarang alami dan sarang semi alami dianalisis dengan menggunakan uji $\mathrm{t}$ (independent sample $t$ test). Hasil penelitian menunjukkan kondisi sarang terbaik untuk keberhasilan penetasan telur Penyu Lekang (Lepidochelys olivacea) yang akan dibahas pada aspek $\mathrm{pH}$, suhu dan kelembaban.

\section{HASIL DAN PEMBAHASAN}

Persentase daya tetas telur Penyu Lekang tiap sarang di sarang alami pantai Boom, 
Banyuwangi dan sarang semi alami milik BSTF dapat dilihat pada tabel 1 . Hasil analisis data terhadap perbandingan tingkat keberhasilan penetasan antara sarang alami dan sarang semi alami menggunakan uji $\mathrm{t}$ (independent sample $t$ test) disajikan dalam tabel 2.

Tabel 1. Persentase keberhasilan penetasan telur Penyu Lekang pada sarang alami dan semi alami

\begin{tabular}{lcccc}
\hline Jenis Sarang & $\begin{array}{c}\text { Jumlah } \\
\text { Telur }\end{array}$ & $\begin{array}{c}\text { Telur } \\
\text { Menetas }\end{array}$ & $\begin{array}{c}\text { Telur Tidak } \\
\text { Menetas }\end{array}$ & $\begin{array}{c}\text { Hatching } \\
\text { Success (\%) }\end{array}$ \\
\hline Alami & 10 & 8 & 2 & $80 \%$ \\
Semi Alami & 10 & 0 & 10 & $0 \%$ \\
\hline
\end{tabular}

Tabel 2. Uji t tingkat keberhasilan penetasan telur Penyu Lekang

\begin{tabular}{rccc}
\hline & $\mathrm{df}$ & $\mathrm{t}$ & $\mathrm{t}_{\text {tabel }}$ \\
\hline Equal variances assumed & 18 & 6,000 & 2,8 \\
Equal variances not & 9 & 6,000 & 3,25 \\
\hline assumed & &
\end{tabular}

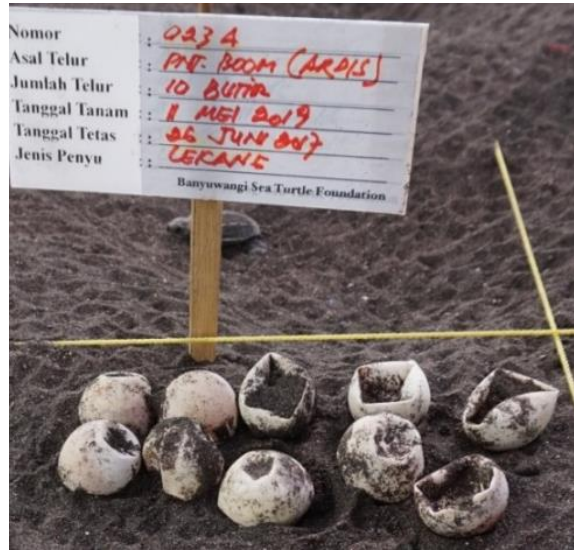

(a)

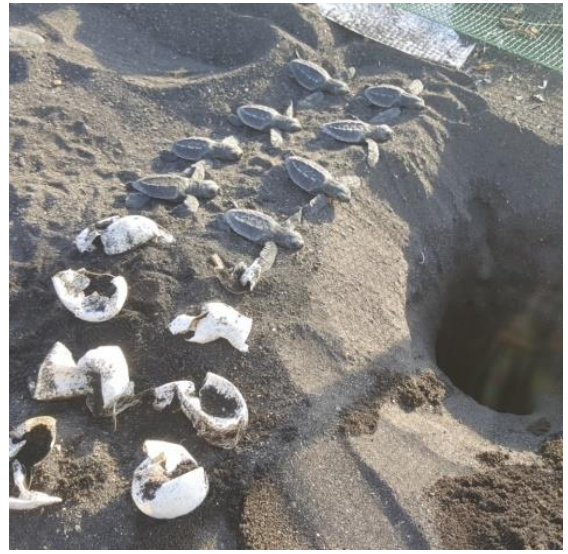

(b)

Gambar 1. Telur gagal menetas pada (a) sarang semi alami; (b) sarang alami

Dari Tabel 2 dapat diketahui bahwa hasil analisis menggunakan uji t pada penetasan telur Penyu Lekang didapatkan terdapat perbedaan yang nyata antara keberhasilan penetasan telur Penyu Lekang secara alami dan semi alami. Pada selang kepercayaan 5\% diperoleh (t) hitung sebesar 6 dan $(\mathrm{t})$ tabel $1 \%$ sebesar 2,8. Hasil menunjukkan bahwa (t) hitung > (t) table $1 \%$. Hasil tersebut menunjukkan bahwa secara statistik penetasan telur Penyu Lekang secara alami menghasilkan lebih banyak tukik dibandingkan dengan penetasan secara semi alami. Perbedaan persentase daya tetas telur Penyu Lekang antara sarang alami dan sarang semi alami pada penelitian ini dipengaruhi oleh beberapa faktor kondisi lingkungan, seperti suhu, kelembaban dan $\mathrm{pH}$.
Lokasi sarang alami menunjukkan rata-rata suhu mulai dari $31,39^{\circ} \mathrm{C}$ hingga $33,45^{\circ} \mathrm{C}$, sedangkan suhu sarang penetasan pada sarang semi alami menunjukkan rata-rata suhu mulai dari $31,31^{\circ} \mathrm{C}$ hingga $32,32^{\circ} \mathrm{C}$. Berdasarkan hasil pengamatan dan pengukuran suhu yang didapatkan pada sarang alami dan sarang semi alami tidak menunjukkan suhu yang yang terlalu tinggi ataupun rendah sehingga seharusnya persentase daya tetas yang didapatkan seluruhnya berada diatas $50 \%$ namun pada penelitian tersebut, persentase daya tetas pada sarang semi alami menunjukkan kegagalan menetas $100 \%$ dan menunjukkan persentase yang berbeda nyata dengan sarang alami yang menunjukkan kegagalan penetasan 20\%, sehingga dapat dikatakan terdapat faktor lain 
yang mempengaruhi kegagalan penetasan telur Penyu Lekang (Lepidochelys olivacea).

Kelembaban pasir pada sarang alami dan sarang semi alami diukur menggunakan soil tester dengan rentang kelembaban 1-8\% RH. Pengukuran diawali dengan menggali pasir di sekitar sarang dengan kedalaman yang sama. Menurut Satriadi dkk. (2004) kelembaban sarang yang baik untuk penetasan telur penyu adalah 4$6 \%$ RH. Pendapat tersebut bertolak belakang dengan hasil penelitian. Kelembaban pasir pada sarang alami menunjukkan rata-rata 1,3-1,36\% RH dengan (hatching success) $80 \%$ sedangkan sarang semi alami menunjukkan rata-rata 6,636,27\% RH dengan (hatching success) $0 \%$.

Perbedaan rata-rata kelembaban dan daya tetas yang mencolok antara sarang alami dan semi alami dikarenakan lokasi penetasan pada sarang alami yang berjarak $33 \mathrm{~m}$ dari bibir pantai dan terkena oleh cahaya matahari secara langsung. Berbeda dengan sarang semi alami yang berjarak $96 \mathrm{~m}$ dari bibir pantai. Tingginya nilai rata-rata kelembaban pada sarang semi alami tersebut dikarenakan Standart Operasional Prosedur (SOP) dari pihak Banyuwang Sea Turtle Foundation (BSTF), yaitu penyiraman sarang semi alami satu kali dalam tiga minggu dengan air. Pergantian pasir di sarang semi alami BSTF, membuat ukuran partikel pasir lebih besar dibandingkan pasir pada sarang alami sehingga penyerapan air terjadi dengan cepat dan meningkatkan kadar air pada sarang. Nilai ratarata kelembaban pada sarang semi alami yang lebih tinggi dibandingkan sarang alami menyebabkan terjadinya kegagalan penetasan secara keseluruhan pada telur penyu, meskipun kelembaban dalam rentang yang normal.

Alat ukur $\mathrm{pH}$ pasir pada sarang alami dan sarang semi alami menggunakan alat yang sama pada pengukuran kelembaban pasir. Hasil pengukuran terhadap $\mathrm{pH}$ sarang menunjukkan bahwa sarang semi alami memiliki nilai $\mathrm{pH}$ sarang berkisar 3,8 hingga 3,97 sedangkan sarang alami memiliki nilai $\mathrm{pH}$ sarang berkisar 6,51 hingga 6,77. Sarang semi alami memiliki $\mathrm{pH}$ dibawah 4,5 yang digolongkan sangat asam sedangkan sarang semi alami memiliki $\mathrm{pH}$ berkisar 6,5- 7,5 yang digolongkan netral.
Rendahnya nilai $\mathrm{pH}$ sarang semi alami dapat dikarenakan tercemarnya pasir pada sarang semi alami saat dilakukan pengerukan dan pemindahan pasir dari pantai boom ke sarang semi alami. Pada pasir asam ditemukan kandungan logam dalam jumlah yang besar, adanya kandungan logam tersebut dikarenakan tidak dilakukan pergantian pasir pada tiap periode penetasan sehingga kandungan logam mengendap dan mengganggu keberhasilan penetasan di sarang semi alami.

Perbedaan nilai $\mathrm{pH}$ sarang tersebut menjadi salah satu faktor yang menyebabkan kegagalan penetasan. Pada sarang yang asam ditemukan unsur-unsur beracun yang disebabkan oleh peningkatan kelarutan unsur $\mathrm{Fe}$ dan $\mathrm{Mn}$ pada jumlah yang besar (Sumirat, 2009). Menurut Primasatya dkk. (2013) kandungan logam pada substrat pasir dikhawatirkan dapat berdampak pada kesehatan tukik maupun perkembangan embrio telur.

Masa inkubasi pada penetasan telur Penyu Lekang (Lepidochelys olivacea) adalah selang waktu dari awal oviposisi hingga tukik pertama kali muncul di permukaan sarang (Rudiana dkk., 2004). Faktor yang mempengaruhi masa inkubasi telur Penyu Lekang (Lepidochelys olivacea) selain suhu dan kelembaban adalah tekstur dan komposisi pasir, kadar oksigen dan iklim. Hasil pengamatan masa inkubasi terhadap kedua cara penetasan, antara sarang alami dan sarang semi alami, menunjukkan masa inkubasi telur Penyu Lekang pada sarang alami yaitu 47 hari sedangkan masa inkubasi telur Penyu Lekang pada sarang semi alami dengan batas masa inkubasi 55 hari tidak didapatkan data, karena kegagalan menetas sebesar $100 \%$. Batas masa inkubasi ditetapkan dari masa inkubasi terpanjang telur penyu lekang. Tidak terdapatnya naungan atau atap pada sarang alami di Pantai Boom Banyuwangi membuat masa inkubasi telur penyu menjadi lebih pendek. Nuitja (1992) menyatakan sarang tanpa naungan membuat masa inkubasi terjadi lebih pendek, dikarenakan sinar matahari secara langsung mengenai sarang, sehingga panas dirambatkan ke dalam sarang dengan proses konduksi, konveksi, dan radiasi. 


\section{KESIMPULAN}

Terdapat perbedaan $\mathrm{pH}$, suhu dan kelembaban antara sarang alami dan sarang semi alami yang mempengaruhi masa inkubasi dan daya tetas telur Penyu Lekang.

\section{UCAPAN TERIMA KASIH}

Peneliti mengucapkan terima kasih kepada Banyuwangi Sea Turtle Foundation (BSTF) atas izin yang diberikan untuk melakukan penelitian dan para petugas di Pantai Boom Banyuwangi.

\section{DAFTAR PUSTAKA}

Direktorat Konservasi dan Taman Nasional Laut. 2009. Pedoman Teknis Pengolaan Konservasi Penyu. Satker Direktorat Konservasi dan Taman Nasional Laut. Jakarta Pusat.

Ditmer, M.A. and S.P. Stapleton. 2012. Factors Affecting Hatch Success of Hawksbill Sea Turtles on Long Island, Antigua, West Indies. Plos One.

Lasabuda, Ridwan. 2013. Pembangunan Wilayah Pesisir dan Lautan Dalam Perspektif Negara Kepulauan Republik Indonesia. Jurnal Ilmiah Platax. Manado.
Nuitja, I.N.S. 1992. Biologi dan Ekologi Pelestarian Penyu Laut. IPB Press. Bogor.

Primasatya, E., D. Elfidasari dan I. Sugoro. 2013. Identifikasi Kandungan Logam Berat Pada Pasir Sarang Penyu Hijau (Chelonia mydas). Kalimantan Timur. Research Gate. 4(B):143-150.

Purwanasari, H.N. 2006. Beberapa Karakteristik Reproduksi Penyu Hijau di Pantai Peneluran Sukomade, Taman Nasional Meru Betiri [Skripsi]. Bali. Universitas Udayana.

Rudiana, E., L. Maslukah dan D. Pringgenies. 2005. Tingkat Keberhasilan Penetasan Telur Penyu Sisik Eretmochleys imbricata di Sarang Semi Alami [Skripsi]. Universitas Dipenogoro.

Satriadi, A, Esti R dan Nurul. A. 2004. Identifikasi Penyu dan Studi Karakteristik Fisik Habitat Penelurannya di Pantai Samas, Kabupaten Bantul, Yogyakarta. Jurusan Ilmu Kelautan, Fakultas Perikanan dan Ilmu Kelautan. Universitas Diponegoro. 8(2):6975 .

Sumirat, Viana. 2009. Dinamika, Eh, pH, Mn dan Fe pada tanah tergenang Pengaruh perlakuan gambut saprik [Skripsi]. Fakultas Agrikultur, Institut Pertanian Bogor. Hal 5. 